ASMUS PETERSEN

DIE BEKÄMPFUNG DER ACKERUNKRÄUTER 
Copyright 1951 by Akademie-Verlag GmbH., Berlin Alle Rechte vorbehalton

Ergchienen im Akademie-Verlag GmbH., Berlin NW 7, Sohiffbauerdamm 19 Lizenz-Nr. $156-100 / 30 / 51$

Herstellung : IV/2/14 - VVB Druck - W Wrkdruck Gräfenhainichen - 224 Bestell- und Verlagsaummer : 5061 


\section{FRIEDRICH AEREBOE}

WIDME ICH

DIESE BETRIEBSWIRTSCHAFTLICHE GRUNDLEGUNG DER BEKÄMPFUNG DER ACKERUNKRÄUTER 
